\title{
The Kinetics of Heat-Induced Structural Changes of $\beta$-Lactoglobulin
}

\author{
N. Sava, ${ }^{1}$ I. Van der Plancken, ${ }^{2}$ W. Claeys, ${ }^{2}$ and M. Hendrickx ${ }^{2}$ \\ ${ }^{1}$ Department of Bioengineering, Faculty of Food Science and Engineering, Dunarea de Jos University, \\ Domneasca 111, 800201 Galati, Romania \\ 'Laboratory of Food Technology, Department of Food and Microbial Technology, Katholieke Universiteit Leuven, \\ Kasteelpark Arenberg 22, B-3001 Heverlee, Belgium
}

\section{ABSTRACT}

Heat-induced structural changes of $\beta$-lactoglobulin were studied at temperatures ranging from 67.5 to $82.5^{\circ} \mathrm{C}$, and at $\mathrm{pH} 7.5$. These changes were monitored by measurement of surface hydrophobicity, thiol availability, and protein solubility. Kinetic studies were conducted to quantitatively describe the contribution of hydrophobic and SH/SS interchange reactions to the thermal structural changes of $\beta$-lactoglobulin. Results indicate that $\beta$-lactoglobulin is sensitive to heat-induced interchange reactions with consequences for protein solubility. The extent of changes measured by the increase in surface hydrophobicity and the decrease in slow-reacting SH groups content could be described by a first-order fractional conversion model and were characterized by activation energy values of $233.9 \pm 8.6$ and $148.2 \pm 6.7 \mathrm{~kJ} / \mathrm{mol}$, respectively. The break in the Arrhenius plot suggested in literature for $\beta$-lactoglobulin denaturation was confirmed in this study only for the kinetics of exposed SH groups.

(Key words: $\beta$-lactoglobulin, structural change, surface hydrophobicity, sulfhydryl/disulfide interchange reaction)

Abbreviation key: ANS = 1-aniline 8-naphthalene sulfonate, DTNB = 5, $5^{\prime}$-dithio-bis(2-nitrobenzoic acid), FI = fluorescence intensity.

\section{INTRODUCTION}

Whey proteins are used as food ingredients because of their high nutritional value and interesting physicochemical properties (Kinsella and Whitehead, 1989; Hoffman et al., 1997). $\beta$-Lactoglobulin is the main protein in whey, comprising about $50 \%$ of the total whey proteins in bovine milk. At room temperature and physiological $\mathrm{pH}$ of milk, $\beta$-LG exists mainly as a noncovalently linked dimer stabilized by hydrogen bonds (de

Received October 25, 2004.

Accepted January 27, 2005.

Corresponding author: Marc Hendrickx; e-mail: Marc.Hendrickx @agr.kuleuven.ac.be.
Wit, 1998). It is a water-soluble, globular protein and consists of 162 amino acid residues, including 5 cysteine residues and 2 tryptophan residues $\left(\operatorname{Trp}^{19}\right.$ and $\operatorname{Trp}{ }^{61}$ ) (Kinsella and Whitehead, 1989). Four of the cysteine residues form disulfide bonds $\left(\mathrm{Cys}^{106}{ }^{10} \mathrm{Cys}^{119}\right.$ and $\mathrm{Cys}^{66}$ $\mathrm{Cys}^{160}$ ) and one is a free thiol group, located in position 121. The amino acid sequence of $\beta$-LG reveals that many hydrophobic amino acids are located near the $\mathrm{Cys}^{121}$ group and $\mathrm{Cys}^{106}{ }^{\mathrm{C} y s^{119}}{ }^{19}$, whereas fewer hydrophobic residues are located near $\mathrm{Cys}^{66}{ }_{-\mathrm{Cys}^{160}}{ }^{16 h i}$ mada and Cheftel, 1989). The latter disulfide bond is at the C-terminal side of the polypeptide chain, whereas the former is buried in the inner core of the protein, and is, therefore, less available for intermolecular interchange reactions. In native $\beta$-LG, the free thiol group is masked in the hydrophobic interior of the protein and does not normally participate in a disulfide linkage (Bryant and McClements, 1998). The reactivity of the free thiol group can be markedly increased by protein unfolding induced by, for example, thermal treatment. Then, the free $\mathrm{SH}^{121}$ group promotes SH/S-S interchange reactions principally with the $\mathrm{Cys}^{66}{ }^{6} \mathrm{Cys}^{160}$ bond of the same or of another $\beta$-LG molecule (Anema and McKenna, 1996). These newly formed SS bonds play an important role in the heat-induced aggregation and gelation of $\beta$-LG (Iametti et al., 1995; Anema and McKenna, 1996; Hoffman and van Mill, 1997). Noncovalent interchange reactions (hydrophobic, electrostatic, and steric) may also be involved in this complex process. The thermal denaturation of $\beta$-LG was found to be complex due to association of the nonnative monomeric $\beta$-LG units combined with the irreversible aggregation of its unfolded state. There are numerous reports on the thermal denaturation of $\beta$-LG in buffer solutions or in milk (Shimada and Cheftel, 1989; Laligant et al., 1991; Monahan et al., 1995; Iametti et al., 1996; Galani and Apenten, 1997; Hoffman and van Mill, 1997; Hoffman et al., 1997; Manderson et al., 1999). Although thermal denaturation of $\beta$-LG clearly involves some successive steps, the extent of contribution of both covalent and noncovalent interactions to the aggregation and gelation process is not fully elucidated. Extrinsic factors like $\mathrm{pH}$, temperature, and ionic environment may affect molecular flexibility or stability, and there- 
fore protein-protein interactions (Harwalker and Ma, 1989; de Wit, 1998).

A kinetic study on the heat-induced structural changes in $\beta$-LG should lead to a better understanding of the relationship between heat treatment and its effect on the functional properties of $\beta$-LG, with the perspective of new applications of whey proteins in foods (de la Fuente et al., 2002). Additionally, a kinetic model for the thermal denaturation of $\beta$-LG is important for optimizing heat treatment of milk products so that the desired functional properties are achieved.

The objective of this study was to follow the heatinduced changes in surface hydrophobicity, thiol availability, solubility, and turbidity of $\beta$-LG solutions heated at $\mathrm{pH}$ 7.5. Kinetic studies were performed to quantitatively describe the contribution of hydrophobic and SH/SS interchange reactions to the thermal structural changes of $\beta$-LG.

\section{MATERIALS AND METHODS}

Bovine $\beta$-LG (90\% pure) was obtained from Sigma Chemical Co. (St. Louis, MO). All other chemicals were of analytical grade.

\section{Isothermal Treatment of $\beta$-LG Solutions}

$\beta$-Lactoglobulin solutions $(110 \mu \mathrm{L}$ of $2.5 \mathrm{mg} / \mathrm{mL}$ in $0.02 M$ Tris-HCl buffer, $\mathrm{pH} 7.5$ ) were heated in 1.5$\mathrm{mL}$ flexible centrifuge tubes (Eppendorf, Eppendorf AG, Hamburg, Germany) in a thermostatically controlled water bath at constant temperatures between 67.5 and $82.5^{\circ} \mathrm{C}$ for 1 to $45 \mathrm{~min}$. After heat treatment, samples were immediately transferred to ice-cold water to prevent further denaturation. Analysis of the heat-induced changes was performed exactly 2 min after thermal treatment.

\section{Solubility}

Diluted samples of treated and untreated $\beta$-LG solutions were centrifuged for $15 \mathrm{~min}$ (Eppendorf 201 centrifuge, Eppendorf AG) at $19,900 \times g$ and $4^{\circ} \mathrm{C}$. Protein concentration in the supernatant was determined using Sigma procedure no. TPRO-562. This method of protein quantification is based on the reduction of $\mathrm{Cu}^{2+}$ by protein in an alkaline environment. Bicinchonininic acid forms a colored complex with the $\mathrm{Cu}^{+}$formed. The absorbance of the complex was measured at $562 \mathrm{~nm}$. Bovine serum albumin was used as a standard, and all samples were assayed in duplicate. Solubility was expressed as the percentage of protein content in the supernatant compared with the total protein content of the untreated sample.

\section{Turbidity}

Turbidity was determined spectrophotometrically after diluting the samples to $1 \mathrm{~mL}$ in $0.02 \mathrm{M}$ Tris- $\mathrm{HCl}$ buffer, at a wavelength of $600 \mathrm{~nm}$ and $20^{\circ} \mathrm{C}$. One hundred percent turbidity was defined as $0 \%$ transmission of light.

\section{Surface Hydrophobicity}

The surface hydrophobicity $\left(\mathrm{S}_{0}\right)$ was determined spectrofluorometrically using 1-aniline 8-naphthalene sulfonate (ANS). A stock solution of ANS ( $8 \mathrm{mM})$ was prepared in $0.1 M$ phosphate buffer $(\mathrm{pH}$ 7.6). The treated and untreated protein solutions were diluted with the phosphate buffer $(\mathrm{pH}$ 7.6) to a final protein concentration in the range of 0.002 to $0.0125 \%$. Excitation and emission wavelengths were fixed at 390 and $470 \mathrm{~nm}$, respectively, with $5-\mathrm{nm}$ slit widths. The relative fluorescence intensity (FI) of the dilutions with and without ANS was measured with a Cary-Eclipse spectrofluorimeter (Varian, Mulgrave, Victoria, Australia). The net relative FI for each sample was then calculated by subtracting the relative FI attributed to protein in buffer. The initial slope of the net relative FI vs. protein concentration plot was calculated by linear regression analysis and used as an index for protein surface hydrophobicity (Alizadeh-Pasdar and LiChan, 2000).

\section{Analysis of Sulfhydryl Groups}

The procedure using Ellman's reagent [5,5'-dithio-bis (2-nitrobenzoic acid); DTNB] was applied to determine the sulfhydryl group content. A molar extinction coefficient of $13,600 \mathrm{M}^{-1} \mathrm{~cm}^{-1}$ was used to calculate the amount of SH groups, expressed in $\mu$ moles per gram of protein (Beveridge et al., 1974). Three procedures were followed to determine the amount of total and exposed (surface) $\mathrm{SH}$ groups and free $\mathrm{SH}^{121}$ groups (slow-reacting $\mathrm{SH}$ groups).

Determination of surface and total SH groups. $\beta$-Lactoglobuin solutions from all heat-treatment groups were diluted with $990 \mu \mathrm{L}$ of standard buffer (0.086 $M$ Tris, $0.09 M$ glycine, $4 \mathrm{~m} M \mathrm{Na}_{2}$ EDTA; $\mathrm{pH}=$ 8) for surface $\mathrm{SH}$ groups, or urea (8 $M$ in standard buffer) for total SH groups. To these samples, $10 \mu \mathrm{L}$ of DTNB (4 mg of DTNB/mL of standard buffer) was added. The absorbance at $412 \mathrm{~nm}$ was measured against a reagent blank after 2 min (total $\mathrm{SH}$ groups) or $15 \mathrm{~min}$ (surface $\mathrm{SH}$ groups) at $20^{\circ} \mathrm{C}$ (Ultrospec 2100 pro, Biochrom, Cambridge, UK).

Determination of slow reacting $\mathbf{S H}$ groups. Content of slow reacting $\mathrm{SH}$ groups was determined spectrophotometrically, based on a method described by 
Shimada and Cheftel (1989). The absorbance at $412 \mathrm{~nm}$ was recorded during $30 \mathrm{~min}$ of reaction at $20^{\circ} \mathrm{C}$. The content was obtained using the following pseudo-firstorder equation:

$$
\ln \left[S H_{t}-S H_{r}\right]=-k_{S H} t+\ln \left[S H_{s}\right]
$$

where $\mathrm{SH}_{\mathrm{t}}$ is the content of total $\mathrm{SH}$ groups obtained from the maximum absorbance value, $\mathrm{SH}_{\mathrm{r}}$ is the content of $\mathrm{SH}$ groups that reacts at time $\mathrm{t}, \mathrm{k}_{\mathrm{SH}}$ is the rate constant for the reaction between DTNB and $\mathrm{SH}^{121}$, and $\mathrm{SH}_{\mathrm{s}}$ is the content in slow reacting $\mathrm{SH}$ groups.

\section{Kinetic Data Analysis}

Changes in surface hydrophobicity and thiol availability as a function of heating time could be described by a fractional conversion model (a modified first-order kinetic model):

$$
X_{t}=X_{\infty}+\left(X_{\infty}-X_{i}\right) \exp (-k t)
$$

where $\mathrm{X}_{\infty}$ is the equilibrium value of the response value $\mathrm{X}$ at infinite heating time, and $\mathrm{X}_{\mathrm{i}}$ is the response value of the native protein at time $t=0$.

The temperature dependence of the rate constant, $\mathrm{k}$ (/min) could be described by the Arrhenius equation:

$$
k=k_{\text {ref }} \exp \left[-\frac{E_{a}}{R}\left[\frac{1}{T}-\frac{1}{T_{r e f}}\right]\right]
$$

where $\mathrm{T}$ and $\mathrm{T}_{\mathrm{ref}}$ are the absolute and reference temperature (in degrees $\mathrm{K}$ ), respectively, $\mathrm{k}_{\text {ref }}$ is the rate constant at $\mathrm{T}_{\text {ref }}, \mathrm{E}_{\mathrm{a}}$ is the activation energy $(\mathrm{kJ} / \mathrm{mol})$, and $R$ is the universal gas constant $(8.314 \mathrm{~J} / \mathrm{mol}$ per degree $\mathrm{K}$ ). Kinetic parameters were estimated by nonlinear regression analysis (SAS Institute, 2001).

\section{RESULTS AND DISCUSSION}

\section{Heat-Induced Changes in Solubility and Turbidity of $\beta$-LG Solutions}

Functionality of $\beta$-LG depends on its solubility in aqueous solutions. The major forces that govern the solubility of $\beta-\mathrm{LG}$ are hydrophobic (de la Fuente et al., 1998). The activation of SH groups because of unfolding during heat treatment results in a decrease of protein stability affecting its solubility.

Heating at a temperature between 70 and $75^{\circ} \mathrm{C}$ results in a minimal loss of $\beta$-LG solubility. A decrease in solubility of only 10 to $20 \%$ compared with the native protein was observed after 45 min of heating, probably because at lower temperatures, the intramolecular in-

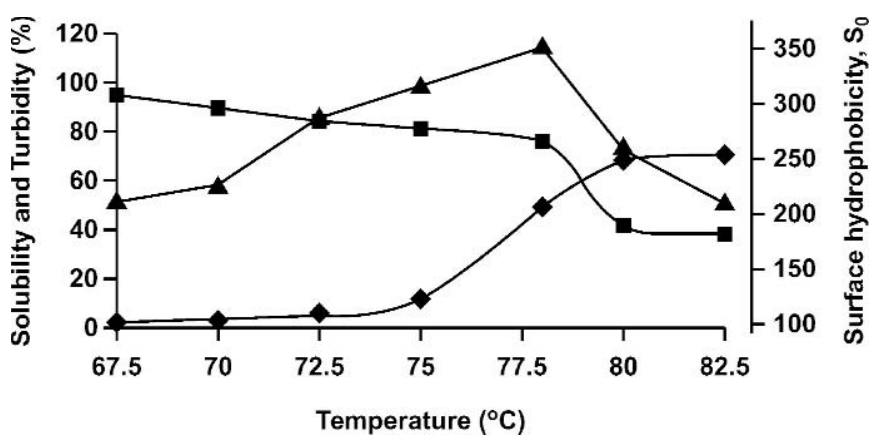

Figure 1. Heat-induced changes in solubility ( $\mathbf{\square})$, turbidity $(\bullet)$, and surface hydrophobicity $(\boldsymbol{\Lambda})$ of $\beta$-lactoglobulin solutions heattreated for $45 \mathrm{~min}$ at different temperatures.

terchange reactions are favored. These results are in good agreement with the data concerning heat-induced changes in turbidity and surface hydrophobicity $\beta$-LG solutions as a function of temperature, as can be seen in Figure 1. The maximum extent of unfolding coincides for all these properties measured above $78^{\circ} \mathrm{C}$. Therefore, partial protein denaturation and its solubility coincide to some extent and good solubility of $\beta$-LG after thermal treatment under neutral conditions and at low ionic strength is theoretically expected (de Wit and Klarenbeek, 1983) and is observed. When too many hydrophobic sites are exposed due to thermal treatment, the hydrophobic interactions are enhanced, usually leading to a decrease in solubility. However, thermal treatment above $80^{\circ} \mathrm{C}$ results in protein aggregation, with a decrease in solubility of $60 \%$. This observation indicates that thermal denaturation of $\beta$ LG as measured by the changes in solubility involves 2 steps: an unfolding step $\left(70\right.$ to $\left.75^{\circ} \mathrm{C}\right)$ and an aggregation step ( 78 to $82.5^{\circ} \mathrm{C}$ ), that mostly follows unfolding, leading to a major decrease in solubility.

\section{Heat-Induced Changes in Surface Hydrophobicity of $\beta$-LG Solutions}

$\beta$-Lactoglobulin contains a high proportion of hydrophobic amino acid side chains, preferentially turned toward the inside of the molecule (Laligant et al., 1991). When the molecule is unfolded, an increase in surface hydrophobicity is expected. The application of the ANS probe can provide information about the structural changes due to heat treatment (Manderson et al., 1999). Thus, the measurement of surface hydrophobicity can be used as an approach for studying the protein-protein interactions (Alizadeh-Pasdar and Li-Chan, 2000), with further application for the manufacturing of gels with different characteristics (Monahan et al., 1995). According to Shimada and Cheftel (1988), unfolding of $\beta$ - 

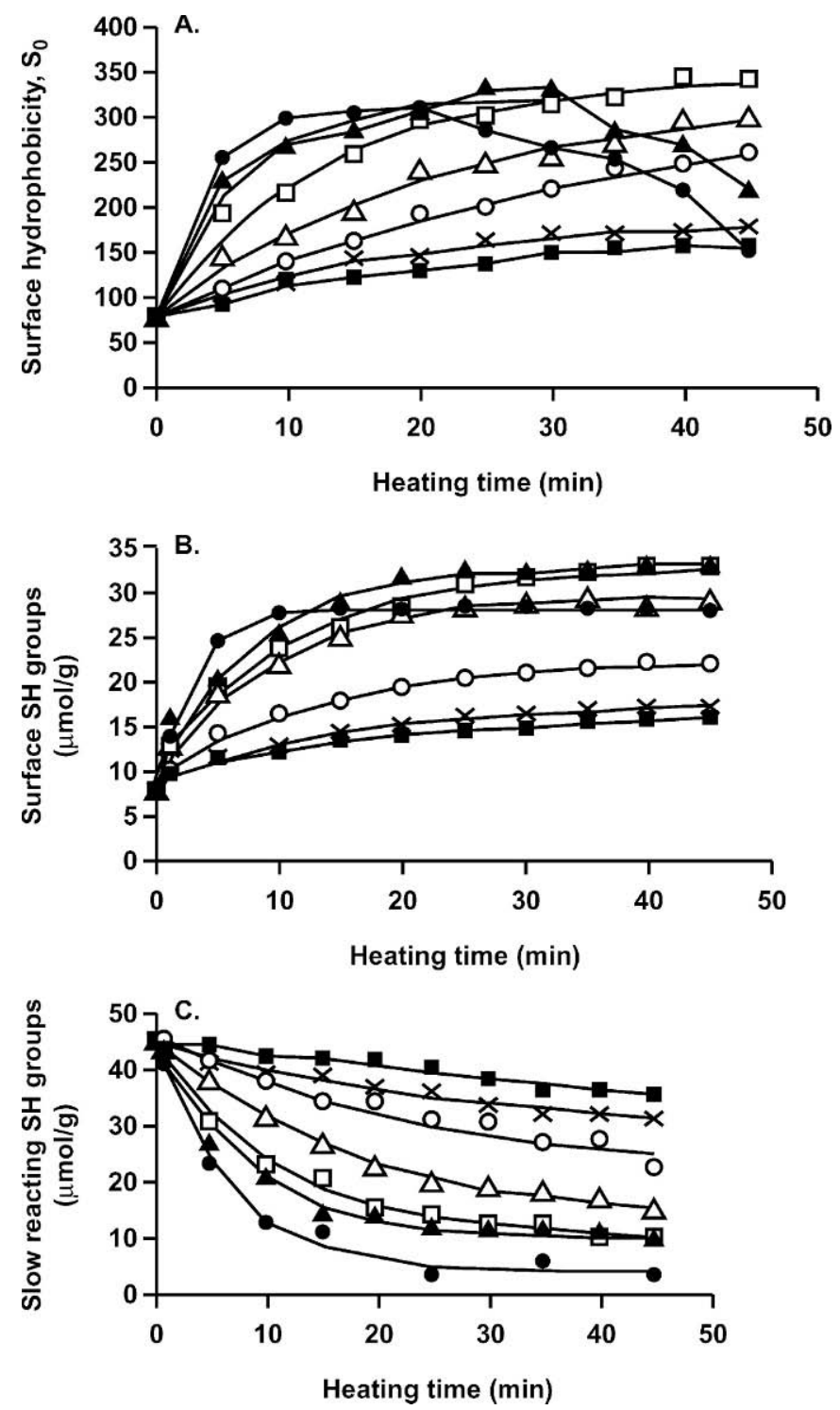

Figure 2. Time-dependent structural changes in $\beta$-lactoglobulin solutions $(2.5 \mathrm{mg} / \mathrm{mL}, \mathrm{pH} 7.5)$ heated at different temperatures $(\mathbf{\square}=$ $67.5^{\circ} \mathrm{C}, \times=70^{\circ} \mathrm{C}, \bigcirc=72.5^{\circ} \mathrm{C}, \triangle=75^{\circ} \mathrm{C}, \square=78^{\circ} \mathrm{C}, \boldsymbol{\Delta}=80^{\circ} \mathrm{C}, \bullet=$ $82.5^{\circ} \mathrm{C}$ ), as described by a first-order fractional conversion kinetic model. A) Surface hydrophobicity $\left(\mathrm{S}_{0}\right)$; B) Surface $\mathrm{SH}$ groups; and C) Slow-reacting SH groups.

LG molecules is followed by protein aggregation, through hydrophobic interactions or SH/SS interchange reactions, or both, leading to a decrease in surface hydrophobicity.

A marked increase in surface hydrophobicity $\mathrm{S}_{0}$ upon heating of $\beta$-LG can be observed in Figure 2a. This implies that during thermal treatment the molecules are unfolded leading to an exposure of the hydrophobic clusters, which can promote intra- and intermolecular interactions. Surface hydrophobicity seems to increase to a plateau value. The maximum value for $\mathrm{S}_{0}$ was 4.2 times higher than the initial values $(78.4 \pm 3.2)$, and was reached after $30 \mathrm{~min}$ of heating at $80^{\circ} \mathrm{C}$. The increase in surface hydrophobicity due to heat treatment is considered a positive attribute for emulsifying and foaming capacities, as long as solubility is not lost (Moro et al., 2001). At 80 to $82.5^{\circ} \mathrm{C}$, however, $\mathrm{S}_{0}$ appears to decrease after reaching this maximum value, as can be seen in Figure 2a. After prolonged heating, too many hydrophobic sites are exposed, increasing the probability of intermolecular hydrophobic interactions, and the protein aggregates. Monahan et al. (1995) and Relkin (1998) observed an increase in surface hydrophobicity for protein that was heated at temperatures between 60 and $85^{\circ} \mathrm{C}$ and 60 and $80^{\circ} \mathrm{C}$, respectively.

\section{Heat-Induced Changes in Thiol Availability of $\beta$-LG Solutions}

Surface thiol groups. The reactivity of the thiol group is strongly dependent on $\mathrm{pH}$. At $\mathrm{pH} 7.5$, the dimer starts to dissociate, followed by critical conformational changes in $\beta$-LG with the exposure of hydrophobic groups and reactive free sulfhydryl group, known as the Tanford transition (Shimada and Cheftel, 1988; Iametti et al., 1996). In the native state, the SH groups of $\beta$-LG are inaccessible to DTNB, although a relatively high level of surface $\mathrm{SH}$ groups was observed in the native protein $(7.91 \pm 0.14 \mu \mathrm{mol} / \mathrm{g}$ of protein). When the temperature is increased, the $\beta$-LG dimer dissociation is enhanced, and the free $\mathrm{SH}$ groups become more accessible for interaction with DTNB. Thus, the rate of polymerization via thiol/disulfide exchange increases (Dannenberg and Kessler, 1988; Monahan et al., 1995). Heat-induced changes of $\beta$-LG solutions between 67.5 and $82.5^{\circ} \mathrm{C}$ caused protein unfolding, as shown by the time- and temperature-dependent increases in the surface $\mathrm{SH}$ groups (Figure $2 \mathrm{~b}$ ). Increasing treatment time resulted in a higher level of SH groups until an equilibrium value was reached. The exposure of $\mathrm{SH}$ groups was more pronounced at higher temperatures. The maximum extent of thiol exposure, expressed as a percentage of the total $\mathrm{SH}$ groups of untreated $\beta$-LG was reached after $45 \mathrm{~min}$ of heating at $80^{\circ} \mathrm{C}$. In this condition, $\sim 65 \%$ of the initial total SH groups was exposed. However, above $80^{\circ} \mathrm{C}$, the formation of disulfide bonds seems to be favored, resulting in a lower level of surfacereactive SH groups after prolonged heating compared with the lower treatment temperatures. These new disulfide bonds are important due to their contribution to the functionality of $\beta$-LG in different food systems (Monahan et al., 1995). Manderson et al. (1999) observed a maximum exposure of $\sim 55 \%$ of total SH groups after heating different genetic variants of $\beta$-LG at $85^{\circ} \mathrm{C}$ for $13.5 \mathrm{~min}$. 
Slow-reacting $\boldsymbol{S H}$ groups. When heating $\beta$-LG, SHSS interchange reactions occur, as well as the exposure of buried SH groups. Theoretically, in heated protein solutions, every cysteine residue can participate in thiol-catalyzed disulfide bond interactions (Hoffman and van Mill, 1997). However, it was shown that blocking the free thiol groups of $\beta$-LG gave a protein derivative that would not aggregate via SH/SS interchange reactions (Iametti et al., 1996; Hoffman and van Mill, 1997). The involvement of the free $\mathrm{SH}^{121}$ groups in the denaturation process of $\beta$-LG has been shown in site-mutagenesis studies, in which $\mathrm{Cys}^{121}$ is substituted with serine. The absence of the $\mathrm{SH}^{121}$ group eliminates the irreversible heat-induced aggregation, confirming the role of $\mathrm{SH}^{121}$ in the early steps of $\beta$-LG denaturation (Jayat et al., 2004).

On the other hand, some authors (McKenzie et al., 1972; Phelan and Malthouse, 1994) have suggested that equal amounts of free $\mathrm{SH}^{121}$ and $\mathrm{SH}^{119}$ are implicated in SH/SS interchange reactions with the $\mathrm{Cys}^{66}{ }^{6} \mathrm{Cys}^{160}$ bond. Shimada and Cheftel (1989) observed that the free $\mathrm{SH}^{121}$ group in native $\beta$-LG reacts slowly with DTNB in urea when SDS is present. This may be explained by the reversible interaction between SDS and the hydrophobic region near the $\mathrm{SH}^{121}$ group, resulting in an inhibition of reaction between the SH group and DTNB. They also explained that the slow-reacting SH groups are mainly $\mathrm{SH}^{121}$ but may be $\mathrm{SH}$ groups in the 119-position. In the unfolded state, the environment near to the newly formed $\mathrm{SH}^{119}$ due to the SH/SS interchange reactions is likely to be similar to that near to the native $\mathrm{SH}^{121}$ groups. When these interactions occur between $\mathrm{SH}^{121}$ and the $\mathrm{Cys}^{66}{ }^{6} \mathrm{Cys}^{160}$ bond, the newly formed $\mathrm{SH}$ group is no longer surrounded by hydrophobic residues. Therefore, the reaction with DTNB in the presence of SDS will be faster compared with the reaction in the native protein. If $\beta$-LG samples contain native and heat-induced displaced SH group, the reactions with DTNB will represent the sum of slow and fast reactions (the so-called slow-reacting $\mathrm{SH}$ groups).

The initial slow-reacting SH group content was found to be $45.46 \pm 0.37 \mu \mathrm{mol} / \mathrm{g}$ of $\beta-\mathrm{LG}$, representing $90.5 \%$ of the initial total $\mathrm{SH}$ groups. This indicates that the $\mathrm{SH}$ groups in the commercial $\beta$-LG are already exposed (as discussed earlier), and are partly implicated in SH/ SS interchange reactions during preparations. The decrease in the amount of slow-reacting $\mathrm{SH}$ groups is depicted in Figure 2c, indicating SH/SS interchange reactions between a heat-modified monomer and a native, undenatured one, as described by the polymerization mechanism (Roefs and De Kruif, 1994). In this case, the newly SH group formed in position 66 or 160 was more available for interactions with DTNB even in the presence of SDS. Creighton (1984) argued that at

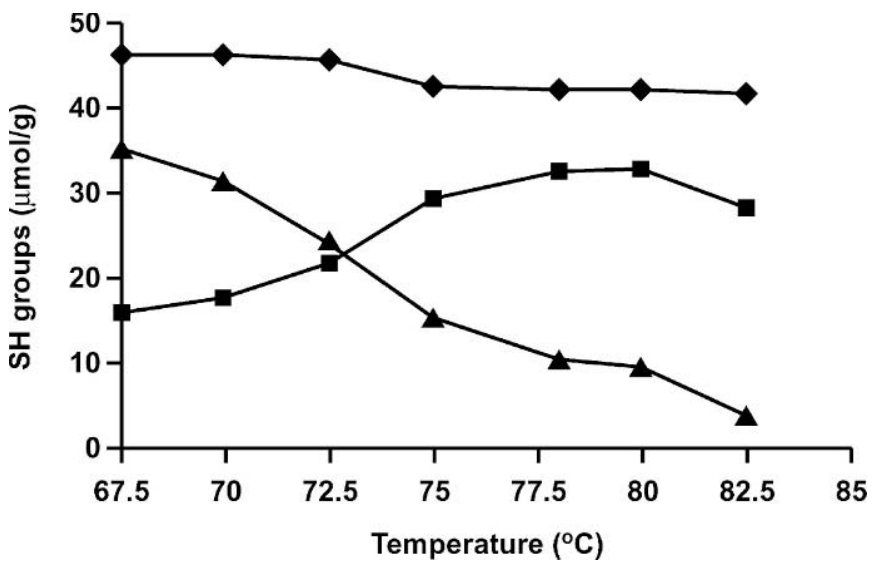

Figure 3. Changes in sulfhydryl content after $45 \mathrm{~min}$ of heating as a function of temperature; $=$ total $\mathrm{SH}$ groups; $\boldsymbol{\square}=$ surface $\mathrm{SH}$ groups, $\boldsymbol{\Delta}$ = slow reacting $\mathrm{SH}$ groups.

low protein concentration (0.05 to $0.2 \%)$ and sufficient reactivity of thiol groups, the formation of intramolecular disulfide bonds would prevail over intermolecular $\mathrm{SH} /$ disulfide interchange reactions. Considering the minimal increase in turbidity of $\beta$-LG solutions heated between 70 and $75^{\circ} \mathrm{C}$, the intramolecular interchange reactions seem to be favored. Above $75^{\circ} \mathrm{C}$, the intermolecular interchange reactions predominated, leading to the polymerization of heat-modified molecules, as can be observed in the increased turbidity of the samples (Figure 1).

The observed pseudo-first-order rate constant $\left(\mathrm{k}_{\mathrm{SH}}\right)$ for the reaction between DTNB and slow-reacting groups of $\beta$-LG in the presence of SDS at neutral $\mathrm{pH}$ was found to decrease from $0.255 \pm 0.001$ (/min) for the native protein to $0.119 \pm 0.014(/ \mathrm{min})$ for the heattreated protein at $82.5^{\circ} \mathrm{C}$ for $35 \mathrm{~min}$. These results contrast with those reported by Shimada and Cheftel (1989). They observed a constant rate for the reaction between DTNB and slow-reacting SH groups after heating of $0.1 \% \beta$-LG solutions at $85^{\circ} \mathrm{C}$ for 0 to $45 \mathrm{~min}$. An explanation could be that at higher temperatures, the environment of $\mathrm{SH}^{121}$ groups is changing, leading to different reactivity of $\mathrm{SH}^{121}$ in the presence of SDS. However, the remaining amount of slow-reacting $\mathrm{SH}$ groups after $45 \mathrm{~min}$ of heating at $82.5^{\circ} \mathrm{C}$ was only 2.94 $\mu \mathrm{mol} / \mathrm{g}$ of protein.

Total SH groups. The total SH groups content for pure $\beta$-LG is reported to be $54.6 \mu \mathrm{mol} / \mathrm{g}$ of protein (Brunner, 1977). In our study, a similar value of $50.9 \pm 0.7$ $\mu \mathrm{mol} / \mathrm{g}$ of proteins was found for native protein. The formation of intermolecular S-S bonds due to SH oxidation during thermal treatment could be neglected, as shown by the marginal decrease in total $\mathrm{SH}$ groups, compared with the decrease in slow-reacting $\mathrm{SH}$ groups (Figure 3). However, after $45 \mathrm{~min}$ of heating at $82.5^{\circ} \mathrm{C}$, 
Table 1. Kinetic parameters $\mathrm{k}$ (rate constant) and $\mathrm{E}_{\mathrm{a}}$ (activation energy) of the first-order fractional conversion model describing heat-induced changes in surface and slow-reacting SH groups and surface hydrophobicity. $^{1}$

\begin{tabular}{lclc}
\hline & \multicolumn{3}{c}{$k(/ \mathrm{min})$} \\
\cline { 2 - 4 } Temperature $\left({ }^{\circ} \mathrm{C}\right)$ & $\begin{array}{l}\text { Surface } \\
\text { hydrophobicity }\end{array}$ & $\begin{array}{l}\text { Surface } \\
\text { SH groups }\end{array}$ & $\begin{array}{l}\text { Slow-reacting } \\
\text { SH groups }\end{array}$ \\
\hline 67.5 & $0.039 \pm 0.007$ & $0.0574 \pm 0.0159$ & $0.00114 \pm 0.008$ \\
70 & $0.0155 \pm 0.006$ & $0.0615 \pm 0.0146$ & $0.0258 \pm 0.0107$ \\
72.5 & $0.0272 \pm 0.0025$ & $0.0755 \pm 0.0138$ & $0.0372 \pm 0.0112$ \\
75 & $0.048 \pm 0.006$ & $0.1095 \pm 0.0137$ & $0.0581 \pm 0.00431$ \\
78 & $0.0813 \pm 0.0087$ & $0.0899 \pm 0.00749$ & $0.0919 \pm 0.0075$ \\
80 & $0.1616 \pm 0.0224$ & $0.1412 \pm 0.0186$ & $0.1225 \pm 0.0176$ \\
82.5 & $0.2882 \pm 0.0176$ & $0.3485 \pm 0.0159$ & $0.1498 \pm 0.016$ \\
$\mathrm{E}_{\mathrm{a}}(\mathrm{kJ} / \mathrm{mol})$ & $233.9 \pm 8.6$ & $52.18 \pm 13.91^{2}$ & $148.2 \pm 6.7$ \\
& & $314.8 \pm 40.9^{3}$ & \\
\hline
\end{tabular}

\footnotetext{
${ }^{1}$ Values \pm standard errors of regression.

${ }^{2}$ Range $=67.5$ to $78^{\circ} \mathrm{C}$.

${ }^{3}$ Range $=78$ to $82.5^{\circ} \mathrm{C}$.
}

the total $\mathrm{SH}$ group content was $41.87 \pm 0.5 \mu \mathrm{mol} / \mathrm{g}$, representing $82.3 \%$ of the total $\mathrm{SH}$ groups for untreated protein. An explanation for the decrease in the total $\mathrm{SH}$ group content could be that at higher temperatures, the denatured $\beta$-LG molecules may be involved in thiol oxidation reactions as well as in intermolecular interchange reactions. These results are in agreement with the observation concerning the role of intermolecular oxidation and thiol/disulfide interchange reactions in the heat-aggregation process of $\beta$-LG molecules, reported in the literature (Shimada and Cheftel, 1989; Monahan et al., 1995; Iametti et al., 1996; Relkin, 1998).

\section{Kinetics of Heat-Induced Changes in Surface Hydrophobicity of $\beta$-LG}

The first-order fractional conversion model could be applied to describe the heat-induced changes in surface hydrophobicity of $\beta$-LG, as shown in Figure 2a. The rate constants ( $\mathrm{k}$ values) for this model are given in Table 1 . Between 70 and $82.5^{\circ} \mathrm{C}$, the temperature dependence of $k$ could accurately be described by the Arrhenius equation (equation 3), resulting in activation energy of $233.9 \pm 8.6 \mathrm{~kJ} / \mathrm{mol}\left(\mathrm{r}^{2}=0.9945\right.$; Figure $\left.4 \mathrm{a}\right)$. It should be noted that at 80 and $82.5^{\circ} \mathrm{C}$, this model was applied only for the increase in surface hydrophobicity, without taking into account the decrease in $\mathrm{S}_{0}$ after prolonged heating time. Given the differences in experimental conditions and analytical methods, a comparison with data from literature was difficult. The present value for $\mathrm{E}_{\mathrm{a}}$ was consistent with the $\mathrm{E}_{\mathrm{a}}$ range for skimmed and whole milk (265 to $280 \mathrm{~kJ} / \mathrm{mol}$ ) in the temperature range of 75 to $95^{\circ} \mathrm{C}$ as reported by Dannenberg and Kessler (1988) and Anema and McKenna (1996), but it is much lower than the $\mathrm{E}_{\mathrm{a}}$ value reported by Galani and Apenten (1997) for thermal denaturation of $\beta$-LG in Tris-HCl buffer in the same temperature range $(376.09 \mathrm{~kJ} / \mathrm{mol})$.

\section{Kinetics of Heat-Induced Changes in Thiol Availability of $\beta$-LG}

The time-dependent changes in the surface and slowreacting thiol content of $\beta$-LG are shown in Figure 2
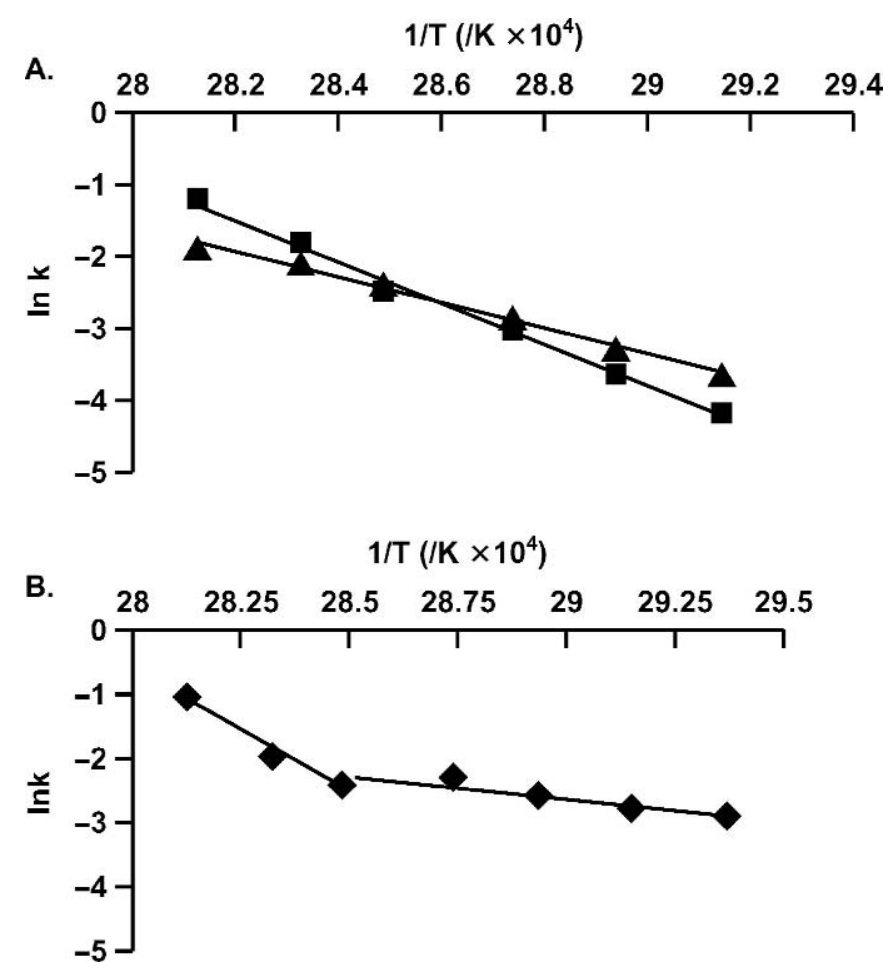

Figure 4. The temperature dependence of the rate constant $(k, /$ min) describing changes in A) Surface hydrophobicity (ם) and slowreacting $\mathrm{SH}$ groups content $(\mathbf{\Lambda})$; B) Surface $\mathrm{SH}$ groups. 
for the different thermal treatments. The decrease in slow-reacting SH groups content could be described by a first-order fractional conversion model. The kinetic parameters are summarized in Table 1 . The temperature dependence of the $k$ values in the temperature range of 70 to $82.5^{\circ} \mathrm{C}$ (Figure 4a) could be described by the Arrhenius equation (equation 3), resulting in an activation energy of $148.19 \pm 6.7 \mathrm{~kJ} / \mathrm{mol}\left(\mathrm{r}^{2}=0.991\right)$. Apenten and Chee (2004), who used a method based on $\kappa$-casein-DTNB complex to measure the activation of $\mathrm{SH}$ groups in $\beta$-LG solution in the temperature range 25 to $55^{\circ} \mathrm{C}$, reported an $\mathrm{E}_{\mathrm{a}}$ of $114.1 \mathrm{~kJ} / \mathrm{mol}$. The present values for $k$ (Table 1) are comparable with those reported by Koka et al. (1968) for heated skimmed milk.

In contrast with the temperature dependence of the $k$ values describing heat-induced changes in surface hydrophobicity and slow reacting $\mathrm{SH}$ groups, kinetics describing the heat induced-changes in surface $\mathrm{SH}$ groups of $\beta$-LG solutions showed a break in the Arrhenius plot around $80^{\circ} \mathrm{C}$ (Figure $4 \mathrm{~b}$ ), resulting in a clear distinction of $\mathrm{E}_{\mathrm{a}}$ values in the 2 temperature ranges studied (Table 1). This may be due to the complexity of the irreversible thermal denaturation process of $\beta$ LG, involving a number of successive reaction steps. A possible model for the thermal behavior of $\beta$-LG in buffer involves 3 steps as reported by Roefs and De Kruif (1994). The early step is the dissociation of the dimer to monomer favored at neutral $\mathrm{pH}$, followed by a heat-induced unfolding step with the exposure of the free reactive thiol group and hydrophobic residues. The last step involves the aggregation of the molecules, due to sulfhydryl/disulfide interchange and noncovalent reactions. The Arrhenius plot becomes nonlinear above the transition temperature, which may be due to the heat-induced aggregation of the protein and expressed in the second part of the curve. Theoretically, if heattreated $\beta$-LG contains a higher amount of free $\mathrm{SH}$ groups, the aggregation step will be favored. In this context, the $\mathrm{E}_{\mathrm{a}}$ value should be lower, as explained by Anema and McKenna (1996). They suggest that in an aggregation process in which a few intermolecular bonds are formed and the state of order of the system is increased, $\mathrm{E}_{\mathrm{a}}$ will be lower.

A break in the linear Arrhenius plots around $85^{\circ} \mathrm{C}$ has been reported in the literature (Dannenberg and Kessler, 1988; Anema and McKenna, 1996; Galani and Apenten, 1997; Claeys, 2003). This unusual behavior could be a consequence of different rate-determining steps involving the participation of 2 consecutive reactions in the denaturation process, characterized by 2 different $\mathrm{E}_{\mathrm{a}}$ values, as explained by Anema and McKenna (1996).

By monitoring the kinetics of changes in protein surface hydrophobicity and slow reacting $\mathrm{SH}$ groups con- tent, we observed that the rate constants had approximately the same magnitude in the temperature range 70 to $78^{\circ} \mathrm{C}$ (Table 1). It is possible that the denaturation process in this temperature range is a combination of SH/SS interchange reactions and noncovalent associations (and probably not only hydrophobic, but also van der Waals and ionic interactions) of the unfolded protein molecules, which can occur simultaneously or sequentially. Our results confirmed the hypothesis that in lower temperature ranges $\left(67.5\right.$ to $\left.78^{\circ} \mathrm{C}\right)$, the ratedetermining step is the unfolding of the molecules, whereas at higher temperatures $\left(78\right.$ to $\left.82.5^{\circ} \mathrm{C}\right)$, the aggregation process involving unfolded molecules becomes rate determining. Our suggestion is that the hydrophobic interactions have a relatively higher contribution for the thermal sensitivity of $\beta$-LG in buffer above $78^{\circ} \mathrm{C}$, leading to the unfolding of the molecules, which is accompanied, probably immediately, by the intermolecular interchange reactions promoted by the free, highly reactive SH group. Galani and Apenten (1999) suggested that the noncovalent interactions (mainly hydrophobic) become more important to the denaturation mechanism of $\beta$-LG at temperatures close to the break in the Arrhenius plot. These heat-induced modifications were found to affect protein solubility.

\section{CONCLUSIONS}

Upon heating $\beta$-LG at neutral $\mathrm{pH}$, the native dimers start to dissociate into monomers, leading to the exposure of the previously buried hydrophobic amino acids and the single free thiol group. Above $78^{\circ} \mathrm{C}$, this is accompanied by the aggregation of the $\beta$-LG molecules because of sulfhydryl-disulfide interchange reactions and hydrophobic interactions, with consequences for protein solubility.

The findings of this study suggest a first-order fractional conversion model in the temperature range of 70 to $82.5^{\circ} \mathrm{C}$ for surface hydrophobicity and slow reacting $\mathrm{SH}$ groups, as well the existence of a break in the Arrhenius plot showing the temperature dependence of the rate constant $\mathrm{k}$, obtained by monitoring the exposure of $\mathrm{SH}$ groups.

\section{ACKNOWLEDGMENTS}

The authors acknowledge financial support from the European Commission-Marie Curie Host Fellowship (QLK1-CT-2000-60014), the Fund for Scientific Research-Flanders, and the research council of the Katholieke Universiteit Leuven (Leuven, Belgium).

\section{REFERENCES}

Alizadeh-Pasdar, N., and C. Y. Li-Chan. 2000. Comparison of protein surface hydrophobicity measured at various $\mathrm{pH}$ values using 
three different fluorescent probes. J. Agric. Food Chem. 48:328-334.

Anema, S. G., and A. McKenna. 1996. Reaction kinetics of thermal denaturation of whey proteins in heated reconstituted whole milk. J. Agric. Food Chem. 44:422-428

Apenten, O. R. K., and C. Chee. 2004. Sulfhydryl group activation for commercial $\beta$-lactoglobulin measured using k-casein 2 -thio, 5'nitrobenzoic acid. Int. Dairy J. 14:195-200.

Beveridge, T., S. J. Toma, and S. Nakai. 1974. Determination of SHand SS-groups in some food proteins using Ellman's reagent. J. Food Sci. 39:49-51.

Brunner, J. R. 1977. Milk Proteins. Pages 175-208 in Food Proteins. J. R. Whitaker, and S. R. Tannenbaum, ed. AVI Publishing, Westport, CT.

Bryant, C. M., and D. J. McClements. 1998. Molecular basis of protein functionality with special consideration of cold-set gels derived from heat-denatured whey. Trends Food Sci. Technol. 9:143-151.

Claeys, W. 2003. Intrinsic time temperature integrators for thermal and high pressure processing of milk, Ph.D. Thesis. Katholieke Universiteit Leuven, Belgium.

Creighton, T. E. 1984. Proteins: Structure and molecular properties, WH Freeman, New York.

Dannenberg, F., and H. G. Kessler. 1988. Thermodymanic approach to kinetics of $\beta$-lactoglobulin denaturation in heated milk and sweet whey. Milchwissenschaft 43:139-142.

de la Fuente, M. A., H. Singh, and Y. Hemar. 2002. Recent advances in the characterization of heat-induced aggregates and intermediates of whey proteins. Trends Food Sci. Technol. 13:262-274.

de Wit, J. N. 1998. Nutritional and functional characteristic of whey proteins in food products. J. Dairy Sci. 81:597-608.

de Wit, J. N., and G. Klarenbeek. 1984. Effects of various heat treatments on structure and solubility of whey proteins. J. Dairy Sci. 67:2701-2710

Galani, D., and O. R. K. Apenten. 1997. The comparative heat stability of bovine $\beta$-lactoglobulin in buffer and complex media. J. Sci. Food Agric. 74:89-98.

Galani, D., and O. R. K. Apenten. 1999. Heat-induced denaturation and aggregation of $\beta$-lactoglobulin: Kinetics of formation of hydrophobic and disulphide-linked aggregates. Int. J. Food Sci. Technol. 34:467-476.

Harwalker, J., and C. Y. Ma. 1989. Effects of medium composition, preheating, and chemical modification upon thermal behavior of oat globulin and $\beta$-lactoglobulin. Pages $210-251$ in Food proteins. J. E. Kinsella and W. G. Soucie, ed. American Oil Chemists Society, Champaign, IL.

Hoffman, M. A. M., G. Sala, C. Olieman, and K. de Kruif. 1997. Molecular mass distributions of heat-induced $\beta$-lactoglobulin aggregates. J. Agric. Food Chem. 45:2949-2957.

Hoffman, M. A. M., and P. J. J. M. van Mill. 1997. Heat-induced aggregation of $\beta$-lactoglobulin: Role of the free thiol group and disulphide bonds. J. Agric. Food Chem. 45:2942-2948.

Iametti, S., S. Cairolli, B. De Gregori, and F. Bonomi. 1995. Modifications of high-order structures upon heating of $\beta$-lactoglobulin:
Dependence on the protein concentration. J. Agric. Food Chem. 43:53-58.

Iametti, S., B. De Gregori, G. Vecchio, and F. Bonomi. 1996. Modifications occur at different structural levels during the heat denaturation of $\beta$-lactoglobulin. Eur. J. Biochem. 237:106-112.

Jayat, D., J. C. Gaudin, J. M. Chobert, T. V. Burova, C. Holt, I. McNae, L. Sawyer, and T. Haertlé. 2004. A recombinant C121S mutant of bovine $\beta$-lactoglobulin is more susceptible to peptic digestion and to denaturation by reducing agents and heating. Biochemistry 43:6312-6321.

Kinsella, N., and D. M. Whitehead. 1989. Proteins in whey: Chemical, physical, and functional properties. Adv. Food Nutr. Res. 33:343-438.

Koka, M., E. M. Milolajcik, and I. A. Gould. 1968. Spectrophotometric method for determination of heat-activated sulfhydryl groups of skim milk. J. Dairy Sci. 51:217-219.

Laligant, A., E. Dumay, C. C. Valencia, L. L. Cuq, and J. C. Cheftel. 1991. Surface hydrophobicity and aggregation of $\beta$-lactoglobulin heated under neutral pH. J. Agric. Food Chem. 39:2147-2155.

Manderson, G. A., M. J. Hardman, and L. K. Creamer. 1999. Effect of heat treatment on bovine $\beta$-lactoglobulin A, B and C. Explored using thiol availability and fluorescence. J. Agric. Food Chem. 47:3617-3627.

McKenzie, H. A., G. B. Ralston, and D. C. Shaw. 1972. Location of sulfhydryl and disulfide groups of bovine $\alpha$-lactoglobulin and effects of urea. Biochemistry 24:4539-4547.

Monahan, F. J., J. B. German, and J. E. Kinsella. 1995. Effect of $\mathrm{pH}$ and temperature on protein unfolding and thiol/disulfide interchange reactions during heat-induced gelation of whey proteins. J. Agric. Food Chem. 43:46-52.

Moro, A., C. Gatti, and N. Delorenzi. 2001. Hydrophobicity of whey protein concentrates measured by fluorescence quenching and its relation with surface functional properties. J. Agric. Food Chem. 49:4784-4789.

Phelan, P., and J. P. G. Malthouse. $1994 .{ }^{13} \mathrm{C}$ NMR of the cyanylated $\beta$-lactoglobulins: Evidence that Cys ${ }^{121}$ provides the thiol group of $\beta$-lactoglobulins A and B. Biochem. J. 302:511-516.

Relkin, P. 1998. Reversibility of heat-induced conformational changes and surface exposed hydrophobic clusters of $\beta$-lactoglobulin: Their role in heat-induced sol-gel state transition. Int. J. Biol. Macromol. 22:59-66.

Roefs, S. P. F. M., and C. G. De Kruif. 1994. A model for the denaturation and aggregation of $\beta$-lactoglobulin. Eur. J. Biochem. 226:883-889.

SAS Institute. 2001. SAS User's guide, Statistics. SAS Institute, Inc., Cary, NC.

Shimada, K., and J. C. Cheftel. 1988. Texture characteristic, protein solubility, and sulfhydryl group/disulfide bond content of heatinduced gels of whey protein isolate. J. Agric. Food Chem. $36: 1018-1025$.

Shimada, K., and J. C. Cheftel. 1989. Sulfhydryl group/disulfide bond interchange reactions during heat-induced gelation of whey protein isolate. J. Agric. Food Chem. 37:161-168. 